\title{
LIV. On the fallacy of the experiments in which water is said to have been formed by the decomposition of chlorine
}

\author{
Sir H. Davy LL.D. F.R.S.
}

To cite this article: Sir H. Davy LL.D. F.R.S. (1819) LIV. On the fallacy of the experiments in which water is said to have been formed by the decomposition of chlorine, Philosophical Magazine Series 1, 53:253, 326-328, DOI: 10.1080/14786441908652148

To link to this article: $h$ ttp://dx.doi.org/10.1080/14786441908652148

曲 Published online: 23 Jul 2009.

Submit your article to this journal $\pi$

山 Article views: 2

View related articles 


\section{On the Fallacy of the Experiments in which Water is said}

rience, and consequently useful discoveries. In 1796 and two following years he published his ' Researches on combustion, the action of medicines on the animal body, on phosphorus, and fulminating bodies, saccharic acid considered as a reagent, convenient apparatus for making carbonated and other mineral waters, on fulminating gold, on the difference between oxygen and termoxygen, process for making mosaic gold, on urinary calculi, description of a compound still to obtain brandy and alcohol at the same time; on ammoniure of cobalt, and an acid in zaffre, method of obtaining crystallized oxymuriate of lead and of calomel without corrosive sublimate, on ethers, albumen, ammoniures of mercury and zinc,' $A n n$. vols. 10-22. In 1800, he again published ' $A$ table of the modern chemical nomenclature,' which occasioned some controversy : but his principal exertions were directed to galvanic experiments during this and the two following years. Among the papers, however, which he published during this period, may be mentioned his 'Observations on vesicular vapours suspended in air at the freezing temperature, on the conversion of fixed oils into wax, sensibility of plants, a detonating oxymuriate of lead, and on the phosphorism of animal bodies.' In the Memoirs of the Italian Institute for 1806, appeared his 'Observations on the identity of some new characters of carbon with those of the metals,' which have since been so amply illustrated. Many other memoirs and translations of chemical and medical works issued from his pen; and his countrymen now begin to appreciate more justly his merits as a philosopher, when they can no longer enjoy his amiable character as a man. Fortunately for them and the friends of science, his son and successor pursues with success the noble career of his father ; and Brugnatelli's Journal, almost the only scientific periodical work at present published in Italy, may continue to be the vehicle of new discoveries in the arts and sciences, to enlighten and instruct some of the most ingenious, friendly and good-natured people in the world.

LIV. On the Fallacy of the Experiments in which Water is said to have been formed by the Decomposition of Chlorine. By Sir H. DAVY, LL.D. F.R.S.*

Some experiments have been lately communicated to the Royal Society of Edisburgh, from which it has been inferred, that water is formed during the action of muriatic acid gas on certain metals, and consequently, that chlorine is decomposed in this operation.

- From the Philosophical Transactions for 1818, Part I. 
In repeating those experiments, I have ascertained, that the water is derived from sources not suspected by the authors, and that their conclusions are unfounded. To take up the time of the Society by long experimental details and theoretical speculations on such an occasion, will be unnecessary; I shall thenefore only transiently mention the sources of error, and denonstrate their operation by two or three examples.

When muriatic acid gas is passed through flint glass tubes heated to redness, a small quantity of water is formed by the action of the gas on the oxide of lead in the glass, and a smaller quantity by its action on the alkali of the glass: the process being one of double affinity, the hydrogen of the muriatic acid unites to the oxygen of the oxide, and the chlorine combines with the metals.

A copious dew was formed by passing muriatic acid gas through flint glass tubes red hot, and a less copious dew, by passing it through green glass tubes. In the first instance, the glass became opaque, and gained a pearly lustre, and a combination of chlorine and lead sublimed from the hotter into the colder part of the tube. In the second, the surface of the tube became slightly opaque, but no sublimate was formed.

When fine clean iron wire was introduced into such tubes, and made red rot, and muriatic acid gas passed over it, no particular precautions being taken to free the tubes from common air, much more water appeared; but this excess of water principally owed its existence to the combination of hydrogen disengaged from the muriatic acid gas by the iron with the oxygen of the common air. I say, principally, because an inappreciable quantity must have been deposited from the vapour of hydrated muriatic acid in the muriatic acid gas. This was proved by filling the whole apparatus with hydrogen in another experiment, and generating the muriatic acid gas in a retort filled with hydrogen, when the water produced was no more than might have been expected from the action of the muriatic acid gas on the oxide of lead and alkali in the glass. I give the details. Above twentyone grains of the first combination of chlorine and iron were formed; the quantity of moisture collected by bibulous paper, and which was a strong acid solution of the proto-muriate of iron, amounted to less than half a grain, and of this not more than two-thirds could have been water. Now, if chlorine had been decomposed in this operation, the quantity of water ought to have been at least ten times as great.

I have shown by numerous experiments, that in the action of muriatic acid gas upon metals, hydrogen, equal in lulk to half the volume of the gas, is produced; it is therefore evident, that if water had been generated by the action of muriatic acid gas on metals, $\mathrm{X} 4$ 
it must have been the chlorine, or the metal, or both, that were decomposed. As chlorine can be freed from much of its aqueous vapour by dry muriate of lime, which is not the case with muriatic acid gas, it offers a much more unexceptionable substance for experiments of this kind. I passed 23 cubical inches of chlorine slowly through dry muriate of lime into a flint glass tube red rot, containing a green glass tube full of iron wire; the chlorine combined with this iron wire with intense heat; the bright sublimate formed was passed tlurough more iron wire heated to redness, so as to form a considerable quantity of the first compound of chlorine with iron, which, when examined, was found exactly the same as that produced by the action of muriatic acid gas on iron. All the products were heated strongly, and the end of the glass tube kept very cool; but not the slightest $a p$. pearance of moisture was perceptible.

In all these experiments I was assisted by Mr. Faraday of the Royal Institution.

Muriate of ammonia is not altered by being passed through porcelain or glass tubes heated to redness; but if metals be present, it offers similar results to muriatic acid gas. In one experiment, in which muriate of ammonia recently sublimed was used, instead of muriatic acid gas, the appearance of moisture was less than in the experiment on muriatic acid gas, which has been just detailed, and yet there was a considerable action on the oxide of lead in the glass, not only by the muriatic acid, hut likewise by the free hydrogen of the decomposed ammonia.

LV. Olservations on a Species of Limosella recently discovered in the United States, by Dr. Eli IrEs, Professor of Materia Medica and Botany in the Medical Institution of Yale College*.

$\mathbf{T}$ CHes small plant was observed in flower in July 1816 , by $\mathrm{Mr}$. Horutio N. Fenn (now of Rochester, state of New-York), in company with Dr. Leavenworth. The plant and the seeds have been preserved by me in a flower-pot from that time to the present. The plant was taken a few rods south of Mr. Whituey's gunmanufactory, on the margin of the river, where it was covered by every tide. I have since observed the plant in great abundance on the margin of the Honsatonuc in Derby, and in those small streams in East Haven, Branford and Guildford, which empty into Long Island Sound.

A specimen of the Limosella (with some specimens of the Tillea) was sent to $Z$. Collins, esq. of Philadelphia, who wrote me that Mr. Nuttal had found the same plant a few days previous

- From the American Journal of Science, No. I. 